\title{
Prevalence of Aspirin Resistance in Patients of Chronic Kidney Disease
}

\author{
Amitabh Dasha, d, Rituparna Maiti ${ }^{\mathrm{b}}$, Tejaswi Kumar AB ${ }^{\mathrm{a}}$, Rohit Ghatule ${ }^{\mathrm{a}}$, Jai Prakash ${ }^{\mathrm{c}}$
}

\begin{abstract}
Background: Chronic renal failure (CRF) is associated with increased risk of cardiovascular morbidity and mortality. Antiplatelets especially low dose aspirin becomes mandatory for prevention of primary and secondary prevention of cardiovascular events in patients of CKD. The aim of this study was to explore the prevalence of aspirin resistance in $\mathrm{CRF}$.
\end{abstract}

Methods: A prospective clinical study was conducted in which 130 patients suffering from CRF with concomitant cardiovascular risk factors were recruited and were on aspirin (100 mg daily) for 4 weeks. Aspirin non-responder status was identified by PFA-100 system.

Results: Aspirin resistance was detected in 53 patients undergoing hemodialysis, 32 patients with stage 3-4 CKD and 22 controls. The frequency of aspirin resistance was significantly higher in the CRF group compared with controls $(34.7 \%$ vs. $16.9 \%, \mathrm{P}<0.001)$ and in hemodialysis patients (46.1\%) compared with stage 3-4 CKD patients $(24.6 \%, \mathrm{P}<0.001)$ and controls $(16.9 \%, \mathrm{P}<0.001)$. Multivariate analysis revealed female sex (odds ratio $(\mathrm{OR})=2.201 ; 95 \%$ confidence interval $(95 \% \mathrm{CI}), 1.173-4.129$; $\mathrm{P}=0.014)$, hemodialysis $(\mathrm{OR}=3.636 ; 95 \% \mathrm{CI}, 1.313-10.066 ; \mathrm{P}=0.013)$ and $\mathrm{HDL}$ cholesterol $(\mathrm{OR}=0.974 ; 95 \% \mathrm{CI}, 0.950-0.999 ; \mathrm{P}=0.043)$ as independent predictors of aspirin resistance in this cohort of patients.

Conclusions: Patients with CRF have higher frequency of aspirin resistance. This might further increase the risk of cardiovascular

Manuscript accepted for publication June 12, 2011

a Department of Pharmacology, Institute of Medical Sciences, Banaras Hindu University, Varanasi, 221005, India

${ }^{b}$ Prathima Institute of Medical Sciences, Karimnagar, Andhra Pradesh, India

${ }^{c}$ Department of Nephrology, Institute of Medical Sciences, Banaras Hindu University, Varanasi-5, Uttarpradesh, India

${ }^{\mathrm{d} C}$ Corresponding author: Amitabh Dash, Flat No. 603, A Wing, Venus Apartments, Bhakti Park, Wadala, Mumbai -400037, India.

Email: dr.adidash@gmail.com

doi:10.4021/wjnu4w morbidity and mortality in these patients.

Keywords: Chronic renal failure; Aspirin resistance; PFA-100

\section{Introduction}

Low dose aspirin has been implicated to attenuate the risks of myocardial infarction, stroke, and vascular related deaths in patients with cardiovascular disease on long term use [1]. Still a significant number of patients on low dose aspirin as antithrombotic therapy have major adverse vascular related events each year [2]. In most cases lack of patient compliance, low responsiveness or resistances to aspirin fail to reach the therapeutic goal. Though there is no universally accepted definition of aspirin resistance (AR), in clinical terms it is characterized by occurrence of a thrombotic episode despite treatment with aspirin, in pharmacological terms it means insufficient pharmacological inhibition of platelet cyclooxygenase-1 (COX-1) derived thromboxane formation with subsequent insufficient inhibition of platelet function by standard antiplatelet dose of aspirin or a phenomenon where the expected inhibition of platelet responses is not obtained as evaluated by different biological tests [3]. The degree of inhibition of platelet aggregation can be assessed by a variety of tests, such as optical platelet aggregation, PFA-100, expression of platelet surface receptor $[4,5]$.

Chronic kidney disease (CKD) has emerged as a major public health problem of primary importance especially in developing countries [6]. The presence of CKD is one of the most potent known risk factors for cardiovascular disease (CVD). Individuals with CKD have a 10 - to 20 -fold greater risk of cardiac death, mainly because of the high risk for coronary heart disease and other cardiovascular complications which virtually coexists with diabetes, hypertension, obesity, lipid abnormalities, hyperaggregability state and endothelial dysfunction $[7,8]$. CKD in the presence of other co-morbidities like type 2 diabetes mellitus and hypertension can lead to early progression to end stage renal disease (ESRD or stage V CKD), which confers a greater risk for CVD morbidity and mortality. Cardiovascular events are the leading cause of 
Table 1. Baseline Demographic Data and Clinical Characteristics of Patients Participated in the Study

\begin{tabular}{|c|c|}
\hline Parameters & Mean \pm S.D \\
\hline Age (years) & $65.03 \pm 9.02$ \\
\hline Male : Female & $99: 27$ \\
\hline BMI $\left(\mathrm{kg} / \mathrm{m}^{2}\right)$ & $27.78 \pm 4.30$ \\
\hline Patients with Diabetes & 67 \\
\hline Patients with Hypertension & 96 \\
\hline Patients with Hyperlipidemia & 56 \\
\hline Smoker & 37 \\
\hline Systolic Blood Pressure (mmHg) & $147.6 \pm 17.4$ \\
\hline Diastolic Blood Pressure $(\mathrm{mmHg})$ & $93.1 \pm 7.7$ \\
\hline Fasting Blood Sugar (mg/dL) & $115.89 \pm 19.96$ \\
\hline HDL (mg/dL) & $54.42 \pm 9.98$ \\
\hline LDL (mg/dL) & $157.53 \pm 25.82$ \\
\hline TGL (mg/dL) & $166.35 \pm 31.25$ \\
\hline $\mathrm{TC}(\mathrm{mg} / \mathrm{dL})$ & $210.2 \pm 21.73$ \\
\hline Fibrinogen $(\mathrm{g} / \mathrm{L})$ & $2.16 \pm 0.36$ \\
\hline Creatinine Clerance (mL/min) & $35.50 \pm 12.02$ \\
\hline
\end{tabular}

premature death in patients with

CKD even before their progression to ESRD [9], therefore antiplatelets especially low dose aspirin becomes mandatory for prevention of primary and secondary prevention of cardiovascular events in patients of CKD. Studies have indicated that the efficacy of aspirin in primary prevention of cardiovascular events for type 2 diabetic patients was reduced [10], and metabolic syndrome patients were prone to develop cardiovascular disease because of platelet hyperactivity [11] and conferred a higher risk of long term MACCE ( Major Adverse Cardiac and Cerebral Events) in patients with CAD [12]. There is a paucity of studies to evaluate the clinical efficacy and resistance of low dose aspirin in individuals of CKD, a surprise omission despite of number of studies on Aspirin Resistance in many clinical states. In this study we evaluate the prevalence of aspirin resistance in CKD patients.

\section{Methods}

\section{Patients}

All 130 patients were prospectively enrolled between February 2009 and October 2009. The patients presenting to the outpatient clinic for follow-up treatment of CKD were recruited in this study. Concomitant cardiovascular risk factors of these patients were patients with Type 2 Diabetes Mellitus (fasting blood sugar of $\geq 126 \mathrm{mg} / \mathrm{dL}$ ), hypertension (defined as systolic blood pressure $\geq 140 \mathrm{mmHg}$ and diastolic blood pressure $\geq 90 \mathrm{mmHg}$ and/or antihypertensive treatment), hypercholesterolemia (blood cholesterol levels $\geq 200 \mathrm{mg}$ on diet and /or treatment with statins), smoking (currently smoking), obesity (body mass index $>30 \mathrm{~kg} / \mathrm{m}^{2}$ ) and family history (first degree relatives with symptomatic coronary heart disease). Exclusion criteria included ingestion of an- 
Table 2. Comparison Between Aspirin Sensitive and Aspirin Resistant Group to $100 \mathrm{mg}$ Aspirin Taken Daily for 4 Weeks

\begin{tabular}{lccc}
\hline Parameters & $\begin{array}{c}\text { Aspirin Sensitive } \\
(\mathbf{n}=\mathbf{8 7})\end{array}$ & $\begin{array}{c}\text { Aspirin Resistance } \\
(\mathbf{n}=\mathbf{3 9})\end{array}$ & P value \\
\hline Age (years) & $64.37 \pm 9.12$ & $65.70 \pm 8.99$ & 0.57 \\
Male $:$ Female & $70: 17$ & $29: 10$ & 0.69 \\
BMI (kg/m $\left.{ }^{2}\right)$ & $26.27 \pm 3.57$ & $29.30 \pm 4.49$ & $0.005^{*}$ \\
Diabetes & 42 & 25 & 0.1 \\
Hypertension & 64 & 36 & $0.03^{*}$ \\
Hyperlipidemia & 34 & 22 & $0.05^{*}$ \\
Smoker & 22 & 15 & 0.20 \\
SBP (mmHg) & $146.42 \pm 18.32$ & $148.76 \pm 16.92$ & 0.83 \\
DBP (mm Hg) & $92.71 \pm 7.01$ & $93.57 \pm 8.4$ & 0.43 \\
Fasting Blood Sugar (mg/dL) & $108.67 \pm 21.16$ & $123.11 \pm 17.01$ & $0.01^{*}$ \\
HDL (mg/dL) & $55.25 \pm 8.09$ & $53.38 \pm 11.89$ & 0.69 \\
LDL (mg/dL) & $147.2 \pm 21.13$ & $167.87 \pm 34.07$ & $0.05^{*}$ \\
TGL (mg/dL) & $162.27 \pm 34.13$ & $171.43 \pm 27.63$ & 0.43 \\
TC (mg/dL) & $255.27 \pm 36.48$ & $210.20 \pm 21.73$ & 0.61 \\
Fibrinogen (g/L) & $2.01 \pm 0.32$ & $2.31 \pm 0.40$ & $0.04^{*}$ \\
Creatinine Clerance (mL/min) & $39.88 \pm 10.87$ & \\
\hline & & & \\
\hline
\end{tabular}

tiplatelet drugs or other non-steroidal anti-inflammatory drugs, administration of heparin or low-molecular-weight heparin within $24 \mathrm{~h}$ before enrolment; major surgical procedure within one week before enrolment; family or personal history of bleeding disorders; platelet count $<150000 / \mu \mathrm{L}$ or $>450000 / \mu \mathrm{L}$; haemoglobin $<8 \mathrm{~g} / \mathrm{dL}$, history of myeloproliferative disorders; or history of drug-induced thrombocytopenia, patients with end stage renal disease (ESRD) and patients on dialysis.

\section{Study design}

The present study is a 4- week, prospective clinical study conducted in a single centre. The study was carried out by Department of Pharmacology and Department of Clinical
Nephrology in Sir Sunderlal Hospital, Banaras Hindu University, Varanasi, a tertiary care government hospital. The study was approved by Institute Ethical Committee and procedures followed in this study are in accordance with the ethical standard laid down by ICMR's Ethical guidelines for biomedical research on human subjects (2006). A written informed consent was taken from all the patients participated in the study after explaining the patient's diagnosis, the nature and purpose of a proposed treatment, the risks and benefits of a proposed treatment (aspirin), alternative treatment and the risks and benefits of the alternative treatment. All patients were on regular aspirin treatment with $100 \mathrm{mg}$ daily. Compliance on aspirin was determined by pill count method at follow-up. Baseline values were measured before administration of Aspirin and compared with values measured after 
4 weeks of treatment.

\section{Laboratory measurements}

Blood samples were obtained from each subject by antecubital venipuncture in the fasting state in the morning between 8 and 10 a.m., 2 - 4 hours after daily aspirin intake. Citrated blood (0.129 M trisodium citrate in dilution 1:10) was used for PFA-100 analysis (Platelet Function Analyzer, Dade Behring, Germany) and $4.5 \mathrm{~mL}$ blood were collected in EDTA (ethylene-diamine-tetraacetic acid) tubes for platelet count and hematocrit determination. All analyses were performed within 1 - 2 hours after blood collection.

\section{Lipid profile}

Total cholesterol, HDL cholesterol and triglyceride levels were measured enzymatically on a Hitachi 911 autoanalyzer (Hitachi, Japan). LDL cholesterol level was determined using the Friedewald formula.

\section{Platelet function analysis}

The effect of aspirin was assessed using the platelet function analyser (PFA-100) system (Dade-Behring International, Germany). PFA-100 system is a novel platelet function test that enables rapid, simple, and reproducible quantitative assessment of in vitro platelet aggregation and is used for identification of aspirin nonresponder status [13-15]. PFA-100 contains a microprocessor controlled instrument/ test cartridge system that measures in vitro bleeding time. This test is based on a highly sensitive and specific in vitro system for the assessment of platelet aggregation in small samples of citrated whole blood. It uses a disposable test cartridge coated with either collagen or epinephrine or with collagen and adenosine diphosphate (ADP). The instrument aspirates citrated whole blood under a constant vacuum condition at a high shear stress of $5000-6000 \mathrm{~s}^{-1}$ through a capillary tube and a precisely defined aperture in the membrane that mimics microcapillary system of human circulation. Time to complete occlusion of the aperture is defined as the closure time (CT). Normal reference ranges of closure time in our laboratory are $85-165 \mathrm{sec}$ for collagen/epinephrine-coated membrane (EPI). Since aspirin has a prolonged EPI closure time in a dose-dependent fashion, aspirin resistance was defined as EPI closure time of $<186$ sec. All tests were repeated twice.

\section{Safety analysis}

Safety was assessed in terms of reported adverse experiences and vital signs, which were measured at baseline and at the end of the study. All reported adverse drug reactions were graded according to The National Cancer Institute Common
Toxicity Criteria (CTC) and compared between aspirin sensitive and resistant groups.

\section{Statistical analysis}

Data were analyzed using the SPSS statistical software package (15.0 for Windows). Results were expressed as mean \pm standard deviation for continuous data or as percentages and numbers for categorical data. Continuous variables with normal distribution and unequal distribution were analyzed with the Student's t-test. The odds ratios (OR) and 95\% confidence intervals $(\mathrm{CI})$ were calculated. $\mathrm{P}<0.05$ was considered as statistically significant.

\section{Results}

The baseline characteristics of the patients are listed in Table 1. The mean age of patients was $65.03 \pm 9.02$ years. No. of male patients were 101 and female patients were 29. The mean BMI of patients was $27.78 \pm 4.30 \mathrm{~kg} / \mathrm{m}^{2}, 67$ patients were diabetic, 96 patients were hypertensive, 56 patients had hyperliidemia and 37 patients were chronic smokers. Of a total 130 patients enrolled in the study group 4 patients were lost to follow up. Total of 39 patients were aspirin resitant (Table 2). On comparison to Aspirin sensitive group, aspirin resistant group had higher BMI of $29.30 \pm 4.49 \mathrm{~kg} / \mathrm{m}^{2}$ in comparison to aspirin sensitive group $(26.27 \pm 3.57 \mathrm{~kg} /$ $\left.\mathrm{m}^{2}\right)(\mathrm{P}<0.005)$. There was significant no. of hypetensives in aspirin resistant group (92\%) in comparison to aspirin sensitive group $(73 \%)(\mathrm{P}<0.03)$ and significant no. of hyperlipidemic patients in aspirin resistant group (39\%) in comparison to aspirin sensitive group $(56 \%)(\mathrm{P}<0.05)$. The mean fasting blood glucose level was significantly higher in aspirin resistant group $(123.11 \pm 17.01 \mathrm{mg} / \mathrm{dL})$ in comparison to aspirin sensitive group $(108.67 \pm 21.16 \mathrm{mg} / \mathrm{dL})(\mathrm{P}<0.01)$. The mean LDL level in aspirin resistant group $(167.87 \pm 16.92)$ was significantly higher $(\mathrm{P}<0.05)$ in comparison to aspirin sensitive group $(147.2 \pm 21.13)$. The fibrinogen level in aspirin resitant group $(2.31 \pm 0.4)$ was significantly higher than the aspirin sensitive patients $(2.01 \pm 0.32)(\mathrm{P}<0.04)$. Creatinine clearance as calculated by the Cockrauft Gault Formula in aspirin resistant group $(31.13 \pm 13.83 \mathrm{~mL} / \mathrm{min})$ was significantly lower $(\mathrm{P}<0.05)$ in comparison to aspirin sensitive patients $(39.88 \pm 10.87 \mathrm{~mL} / \mathrm{min})$.

\section{Discussion}

Our results show that up to $30.95 \%$ of patients with CKD were aspirin resistant as measured by PFA-100 and is in concordance with the aspirin resistance reported in previous studies as done by PFA-100 [16].

CKD is recognized as independent risk factor for car- 
diovascular events and disease more so with comorbid conditions like diabetes mellitus, hypertension, obesity, hypercholesterolemia and endothelial dysfunction [7, 8] and low dose aspirin becomes essential for primary and secondary prevention of cardiovascular events.

Aspirin resistance is a phenomenon where the expected inhibition of platelet responses is not obtained as evaluated by different biological tests [3] and inability to inhibit thromboxane A2 biosynthesis in vivo and other patient related noncompliance and other factors. Interestingly, in a systematic review done by Krasopoulos et al, the relationship between aspirin resistance and a history of renal impairment was observed [17]. The reason for high aspirin resistance in CKD may be due to abnormality of platelet arachidonic acid metabolism [18] which may lead to altered thromboxane synthesis which is a key factor for the development of resistance to aspirin, considered to be due to the increased activity of phospholipase A2 in the platelets of patients with uraemia [19].

Studies done by Abe et al and Asano et al on animal models have shown that thromboxane play a detrimental role in physiological function of kidney and thromboxane receptors exist in renal vasculature and nephron segments [20, 21]. TXA2 plays a key role in the regulation of renal haemodynamics mainly acting in conjunction with angiotensin II. TXA2, in addition to angiotensin II and arginine-vasopressin constrict larger vessels within the renal vascular tree via activation of a rho-associated kinase pathway [22] and enhanced production of thromboxane in the kidney has been demonstrated in several diseases including lupus nephritis, ureteral obstruction and nephrotoxic renal injury [23-25]. In patients with CKD have higher TXA2 synthesis as compared to that of prostaglandin $\mathrm{I}_{2}$.

In this study Body Mass Index, fasting blood glucose, LDL, Fibrinogen level was significantly higher in aspirin resistant patients in comparison to aspirin responders.

A study done by Ertugrul et al in Type 2 diabetic patients body mass index, fasting blood glucose levels were significantly positively correlated with aspirin resistance and diabetics were more likely to be aspirin resistant than nondiabetics and $100 \mathrm{mg}$ low dose aspirin increased aspirin resistance by $26 \%$ in diabetics than $300 \mathrm{mg}$ aspirin [26]. Diabetes mellitus and hyperglycemia are associated with platelet activation and platelet reactivity [27-29]. Hyperlipidemia patients had poor responsiveness to aspirin therapy as studied by Friend et al. and this may explain the possible causes of aspirin resistance in CKD patients.

This study has some limitations. Inclusion of a small number of patients in both groups was the major limitation. Platelet function was evaluated with only one method. Aspirin resistance was defined only biochemically, but not clinically. It was not a clinical follow-up study.

In conclusion, aspirin resistance was high in patients with CKD in this study. Aspirin resistance is higher espe- cially in CKD patients with high body mass index, increased fasting blood glucose, LDL, fibrinogen levels and decreased Creatinine clearance. Percentage of diabetics, hypertensive and smokers were more in aspirin resistant patients so it will be better to scan this group of patients for aspirin resistance as it seems that CKD patients with comorbid conditions are more prone to aspirin resistance and therapeutic options and strategies should be looked for increasing aspirin dose, alternate or addition of antiplatelet therapies.

\section{Conflict of Interest}

NIL.

\section{Financial Interest}

NIL.

\section{References}

1. Collaborative overview of randomised trials of antiplatelet therapy--I: Prevention of death, myocardial infarction, and stroke by prolonged antiplatelet therapy in various categories of patients. Antiplatelet Trialists' Collaboration. BMJ. 1994;308(6921):81-106.

2. Patrono C, Garcia Rodriguez LA, Landolfi R, Baigent C. Low-dose aspirin for the prevention of atherothrombosis. N Engl J Med. 2005;353(22):2373-2383.

3. Patrono C. Aspirin resistance: definition, mechanisms and clinical read-outs. J Thromb Haemost. 2003;1(8):1710-1713.

4. Lindahl TL, Festin R, Larsson A. Studies of fibrinogen binding to platelets by flow cytometry: an improved method for studies of platelet activation. Thromb Haemost. 1992;68(2):221-225.

5. Peters AJ, Borries M, Gradaus F, Jax TW, Schoebel FC, Strauer BE. In vitro bleeding test with PFA-100-aspects of controlling individual acetylsalicylic acid induced platelet inhibition in patients with cardiovascular disease. J Thromb Thrombolysis. 2001;12(3):263-272.

6. Modi GK, Jha V. The incidence of end-stage renal disease in India: a population-based study. Kidney Int. 2006;70(12):2131-2133.

7. Go AS, Chertow GM, Fan D, McCulloch CE, Hsu CY. Chronic kidney disease and the risks of death, cardiovascular events, and hospitalization. N Engl J Med. 2004;351(13):1296-1305.

8. Sarnak MJ, Levey AS. Cardiovascular disease and chronic renal disease: a new paradigm. Am J Kidney Dis. 2000;35(4 Suppl 1):S117-131.

9. Shulman NB, Ford CE, Hall WD, Blaufox MD, Simon 
D, Langford HG, Schneider KA. Prognostic value of serum creatinine and effect of treatment of hypertension on renal function. Results from the hypertension detection and follow-up program. The Hypertension Detection and Follow-up Program Cooperative Group. Hypertension. 1989;13(5 Suppl):I80-93.

10. Sacco M, Pellegrini F, Roncaglioni MC, Avanzini F, Tognoni G, Nicolucci A. Primary prevention of cardiovascular events with low-dose aspirin and vitamin $\mathrm{E}$ in type 2 diabetic patients: results of the Primary Prevention Project (PPP) trial. Diabetes Care. 2003;26(12):32643272.

11. Ramos F, Baglivo HP, Ramirez AJ, Sanchez R. The metabolic syndrome and related cardiovascular risk. Curr Hypertens Rep. 2001;3(2):100-106.

12. Kahraman G, Sahin T, Kilic T, Baytugan NZ, Agacdiken A, Ural E, Ural D, et al. The frequency of aspirin resistance and its risk factors in patients with metabolic syndrome. Int J Cardiol. 2007;115(3):391-396.

13. Ziegler S, Alt E, Brunner M, Speiser W, Minar E. Influence of systemic inflammation on efficiency of antiplatelet therapy in PAOD patients. Ann Hematol. 2004;83(2):92-94.

14. Homoncik M, Blann AD, Hollenstein U, Pernerstorfer T, Eichler HG, Jilma B. Systemic inflammation increases shear stress-induced platelet plug formation measured by the PFA-100. Br J Haematol. 2000;111(4):12501252.

15. Dalen JE. Aspirin resistance: is it real? Is it clinically significant? Am J Med. 2007;120(1):1-4.

16. Krasopoulos G, Brister SJ, Beattie WS, Buchanan MR. Aspirin "resistance" and risk of cardiovascular morbidity: systematic review and meta-analysis. BMJ. 2008;336(7637):195-198.

17. Bloom A, Greaves M, Preston FE, Brown CB. Evidence against a platelet cyclooxygenase defect in uraemic subjects on chronic haemodialysis. Br J Haematol. 1986;62(1):143-149.

18. Vecino AM, Teruel JL, Navarro JL, Cesar JM. Phospholipase A2 activity in platelets of patients with uremia. Platelets. 2002;13(7):415-418.

19. Abe T, Takeuchi K, Takahashi N, Tsutsumi E, Taniyama
Y, Abe K. Rat kidney thromboxane receptor: molecular cloning, signal transduction, and intrarenal expression localization. J Clin Invest. 1995;96(2):657-664.

20. Asano K, Taniguchi S, Nakao A, Maruyama T, Watanabe T, Kurokawa K. Distribution of thromboxane A2 receptor mRNA along the mouse nephron segments. Biochem Biophys Res Commun. 1996;226(3):613-617.

21. Cavarape A, Bauer J, Bartoli E, Endlich K, Parekh N. Effects of angiotensin II, arginine vasopressin and tromboxane A2 in renal vascular bed: role of rho-kinase. Nephrol Dial Transplant. 2003;18(9):1764-1769.

22. Spurney RF, Fan PY, Ruiz P, Sanfilippo F, Pisetsky DS, Coffman TM. Thromboxane receptor blockade reduces renal injury in murine lupus nephritis. Kidney Int. 1992;41(4):973-982.

23. Yarger WE, Schocken DD, Harris RH. Obstructive nephropathy in the rat: possible roles for the reninangiotensin system, prostaglandins, and thromboxanes in postobstructive renal function. J Clin Invest. 1980;65(2):400-412.

24. Lianos EA, Andres GA, Dunn MJ. Glomerular prostaglandin and thromboxane synthesis in rat nephrotoxic serum nephritis. Effects on renal hemodynamics. J Clin Invest. 1983;72(4):1439-1448.

25. Ertugrul DT, Tutal E, Yildiz M, Akin O, Yalcin AA, Ure OS, Yilmaz H, et al. Aspirin resistance is associated with glycemic control, the dose of aspirin, and obesity in type 2 diabetes mellitus. J Clin Endocrinol Metab. 2010;95(6):2897-2901.

26. Sudic D, Razmara M, Forslund M, Ji Q, Hjemdahl P, Li N. High glucose levels enhance platelet activation: involvement of multiple mechanisms. Br J Haematol. 2006;133(3):315-322.

27. Turkoglu S, Abaci A. [Use of aspirin in diabetic patients]. Anadolu Kardiyol Derg. 2007;7 Suppl 2:5-8.

28. Keating FK, Sobel BE, Schneider DJ. Effects of increased concentrations of glucose on platelet reactivity in healthy subjects and in patients with and without diabetes mellitus. Am J Cardiol. 2003;92(11):1362-1365.

29. Friend M, Vucenik I, Miller M. Research pointers: Platelet responsiveness to aspirin in patients with hyperlipidaemia. BMJ. 2003;326(7380):82-83. 